\title{
Potencial energético da microalga Oedogonium sp. na produção de biocombustível sólido
}

Energy potential of the microalgae Oedogonium sp. in production of solid biofuels

Hivila Maria Pontes Marreiro® ${ }^{1}$; Andressa Sales de Oliveira $\oplus^{2}$; Riuzuani Michelle Bezerra Pedrosa Lopes ${ }^{3}$

${ }^{1}$ Engenheira de Energias Renováveis. Mestranda em Energias Renováveis na Universidade Federal da Paraíba. João Pessoa. Fone: (83) 3216-7200, hivila.marreiro@gmail.com; ${ }^{2}$ Graduanda em Engenharia de Energias Renováveis na Universidade Federal da Paraíba. João Pessoa, andressa.oliveira@ cear.ufpb.br; ${ }^{3}$ Professora Doutora, do Departamento de Engenharia de Energias Renováveis da Universidade Federal da Paraíba. João Pessoa, riuzuani@ cear.ufpb.br.

\section{A R T I G O}

Recebido: $12 / 07 / 2019$

Aprovado: 06/09/2019

\section{Palavras-chave:}

Biomassa

Biocombustível

Pellets

Key words:

Biomass

Biofuel

Pellets

\section{R E S U M O}

As energias renováveis surgem como uma maneira de mitigar os prejuízos ambientais causados pelas tradicionais fontes de energia, propondo também, uma diversificação da matriz energética. Dentre os diversos vetores energéticos possíveis, as microalgas surgem como uma boa opção para geração de energia por possuírem uma alta capacidade de conversão de energia solar em energia química, tornando amplas as possibilidades para obtenção de biomassa algal em aplicações energéticas. Por meio delas é possível produzir biodiesel, bioetanol, gás metano e gás hidrogênio como combustível. O presente trabalho, avalia o potencial energético da microalga Oedogonium sp. por meio de sua análise físico-química e de poder calorífico, assim como a viabilidade da sua densificação em forma de pellets, a fim de aproveitá-la como matéria sólida para combustão. Para isso, foram realizadas análises calorimétrica, termogravimétrica e imediata, onde nessa última foi possível obter os teores de umidade, cinza, carbono fixo e voláteis presentes na biomassa. Os resultados foram satisfatórios, nos quais o poder calorífico superior foi igual a $16,13 \mathrm{MJ} / \mathrm{kg}$, valor superior ao encontrado para lenha comercial e dentro dos padrões impostos pelas normas europeia, sueca e intencional de padronização de pellets.

\section{A B S T R A C T}

Renewable energies arise as a way of mitigating the environmental damages caused by traditional of energy sources, as well as offering a diversification of the energy matrix. Among the many energetic vectors possible, microalgae are a good choice for power generation due to their high conversion capacity of solar energy into chemical energy, broadening the possibilities of obtaining algal biomass in energetic applications. Through them, it's possible to produce biodiesel, bioethanol, methane gas and hydrogen gas as fuel. The present work evaluates the energy potential of the microalga Oedogonium sp. through its physical-chemical analysis and the calorific value, as well as the viability of its densification in the form of pellets, to be used as a solid combustion material. For this, calorimetric, thermogravimetric and immediate analyzes were performed, where in the latter it was possible to obtain the moisture, ash, fixed carbon and volatile contents present in the biomass. The results found in the analyzes were satisfactory, in which the higher calorific value was $16,13 \mathrm{MJ} / \mathrm{kg}$, higher than that found for firewood, and in the standards imposed by European, Swedish and international standards for pellets.

\section{INTRODUÇÃO}

Com o avanço tecnológico e o aumento da população e do poder de consumo é notável o crescimento da demanda energética para atender aos padrões de vida da sociedade (PEREIRA; HORN, 2010). Sabe-se também, que em nome de tais avanços, os recursos naturais vêm sendo explorados em uma velocidade maior que sua capacidade de reposição, podendo causar danos irreversíveis ao meio ambiente (MARTINE et al., 2012).

Diante dos problemas ambientais e energéticos, resultado do consumo desenfreado dos recursos naturais em nome do desenvolvimento, surgem as energias renováveis. Elas apresentam-se como uma alternativa sustentável de produção de

\begin{tabular}{lc}
\hline Revista Verde & v. 14, n.4, out.-dez, p.578-585, 2019 \\
ISSN 1981-8203 & doi: $10.18378 /$ rvads.v14i4.6740 \\
Pombal, Paraíba, Brasil &
\end{tabular}


energia, que graças às políticas ambientais e avanços tecnológicos, estão se tornando cada vez mais atrativas a investimentos, traçando um futuro otimista para produção energética dessa natureza. Suas principais representantes são a biomassa, energia eólica e energia solar.

A biomassa pode ser obtida a partir da matéria orgânica de animais, fungos e vegetais, sendo este último dividido em vegetais lenhosos e não lenhosos, que por sua vez acomoda a subclassificação das algas (CORTEZ et al., 2008). Estes insumos podem ser transformados em gás, líquido ou sólido para gerar energia térmica, elétrica ou combustível por meio de diferentes rotas (DO AMARAL; TAVARES, 2013).

As algas e cianobactérias, por exemplo, produzem proteínas, carboidratos e lipídios que podem ser convertidos em biodiesel e gás hidrogênio (SINGH et al., 2016). Dentre elas, existem mais de 100 mil espécies diferentes classificadas como algas: organismos aquáticos fotossintéticos que necessitam de luz, carboidratos, $\mathrm{N}, \mathrm{P}, \mathrm{K}$ e $\mathrm{CO}_{2}$ para crescerem, e variam em tamanho, forma e cor (SCOTT et al., 2010). Elas se dividem em dois grandes grupos, as macroalgas e as microalgas. Estas últimas são organismos mensurados em micrômetros, compostos por proteínas, lipídios e ácidos graxos, podendo ter outros componentes dependendo da espécie e do local onde se encontram. Com uma estrutura unicelular, estes microrganismos possuem uma simplicidade que lhes permitem a fácil conversão de energia solar em energia química (CARDOSO et al., 2011).

Diante dessa fácil conversão energética, um leque de possibilidades se abre para o aproveitamento da biomassa algal em aplicações comerciais. Muitas microalgas possuem a capacidade de produzir gás hidrogênio por meio da energia solar, e por meio da fermentação da biomassa produzem gás metano (ANDRADE; FILHO, 2014). Algumas delas, como a Botryococcus braunii, Chlorella, Crypthecodinium, Cylindrotheca, Dunaliella e a Isochrysis possuem uma alta capacidade de síntese de lipídeos e alta produção de óleo que se sobressaem em comparação a outras fontes permitindo a geração de diferentes tipos de biocombustíveis como biodiesel e bioetanol (CARDOSO et al., 2011).

O biodiesel produzido por meio de microalgas possui propriedades similares as do diesel fóssil, e do biodiesel a partir de oleaginosas, podendo ser utilizado nos carros de motor a diesel já existente. A produção de óleo varia de acordo com a espécie e com o tipo de cultivo, na qual todas elas são compostas de triglicerídeos, que podem ser convertidos em ésteres metálicos de ácidos graxos. As microalgas que mais se destacam quanto ao conteúdo de triglicerídeos são: Botryococcus braunii, Chlorella vulgaris, Dunaliella tertiolecta, Nannochloropsis sp, Schizochytrium sp e Scenedesmus obliquus (PEREIRA et al., 2012; MENEZES et al., 2013).

As algas se enquadram na $3^{\circ}$ geração da biomassa e são uma forma promissora de produção de biocombustível principalmente por não fazer uso de terras agricultáveis, como é o caso das culturas agrícolas para fins energéticos (CARRIJO et al., 2015). Seu desenvolvimento não requer grandes volumes de água, podendo-se utilizar água salgada, salobra ou mesmo águas residuais, diferentemente dos biocombustíveis de $1^{\circ}$ geração, etanol de caldo de cana e biodiesel de óleo de soja, ou de $2^{\circ}$ geração, etanol de celulose. (BRASIL, B., 2014).
Nos oceanos ocorre cerca de $50 \%$ da absorção de $\mathrm{CO}_{2}$ na Terra, onde muitas vezes sua fixação é maior do que a liberação. Esse processo ocorre na zona eufótica, onde se encontram as microalgas, que são as principais responsáveis pela absorção biológica de $\mathrm{CO}_{2}$ atmosférico (OHSE et al., 2007). Parte do $\mathrm{CO}_{2}$ absorvido é transferido para o fundo do oceano, onde esse fenômeno associado à difusão do dióxido de carbono na água atenua o acúmulo de gases de efeito estufa (HOMIAK; MORESCO, 2014).

Além disso, sua alta capacidade de absorção de $\mathrm{CO}_{2}$ pode ser associada a plantas industriais responsáveis por emitir grandes volumes de $\mathrm{CO}_{2}$ na atmosfera, que pode ser recuperado em processos de fotobiorreatores e lagoas de canais para potencializar a produção de microalga. Essa biomitigação do dióxido de carbono através de microalgas lhes permite uma alta taxa de crescimento e aproveitamento de $\mathrm{CO}_{2}$, tornando-se possível graças à existência de microalgas tolerantes a gases como $\mathrm{NO}_{\mathrm{X}}$ e $\mathrm{SO}_{\mathrm{X}}$, que estão presentes nos gases de combustão (BRENNAN; OWENDE, 2010).

Diante da versatilidade desta biomassa, é importante inteirar-se das suas propriedades visando obter uma resposta do potencial energético que ela tem a oferecer. Para isso, a sua caracterização é uma boa forma de entender o comportamento e a capacidade energética do material.

Este trabalho, por sua vez, visa realizar um estudo sobre o potencial energético da microalga Oedogonium sp. por meio da análise física e química, e do seu poder calorífico, comparandoa com outras biomassas tradicionais. Além disso, decidiu-se avaliar a densificação da matéria em forma de pastilhas, como forma de analisar a viabilidade da produção de pellets.

\section{MATERIAL E MÉTODOS}

A amostra utilizada para realização do estudo foi retirada de tanques localizados num criadouro de peixes ornamentais da espécie Betta splends, situada no bairro do Altiplano em João Pessoa, capital da Paraíba, na região nordeste do Brasil (Figura 1). A microalga em questão é utilizada como agente fitorremediador para purificar a água dos tanques (melhorando a sua qualidade) que contêm os peixes, e este trabalho, por sua vez, vem avaliar o seu potencial energético.

Figura 1: Localização Fixa do Viveiro de peixes no bairro do Altiplano em João Pessoa, Paraíba.

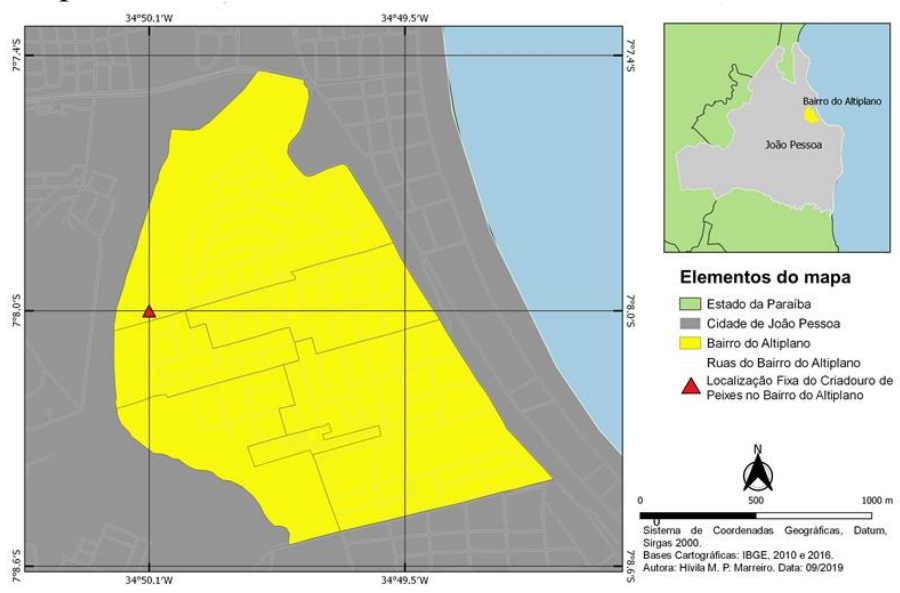

Fonte: Autoras, 2019 
A coleta das amostras foi feita manualmente, no período da tarde, auxiliada por um dos funcionários do criadouro e retiradas diretamente dos tanques continentes dos peixes, que foram escolhidos de maneira aleatória. As microalgas encontravam-se dispostas na superfície da água e na presença de algumas folhas que foram retiradas durante uma limpeza posterior. Assim que coletadas, as algas foram reservadas em recipientes plásticos, sendo mantidas a temperatura ambiente até o momento que foram levadas ao laboratório.

Após a coleta, a amostra da microalga in natura foi levada ao LARBIM (Laboratório de Ambientes Recifais e Biotecnologia com Microalgas) da Universidade Federal da Paraíba - UFPB, na cidade de João Pessoa, Brasil, para confirmação da sua espécie. Diante da análise laboratorial, na qual foi feita a micrografia da alga, constatou-se que a amostra em questão se tratava da microalga de gênero Oedogonium sp, pertencente ao filo Chlorophyta (Figura 2A), que caracteriza-se por seus filamentos cilíndricos não ramificados, com apenas uma célula de espessura e de cor esverdeada, como pode ser melhor observado na micrografia usando a análise de Microscopia Eletrônica (ME) da Figuras 2 B. É normalmente encontrada em corpos de água doce, podendo estar livre e flutuante, ou ligada a outras plantas existentes no ambiente (OEDOGONIUM, 2019).

O gênero acomoda algas de porte grande e microscópicas, podendo ser encontradas em diversas partes do planeta. Cassol et al. (2013) as estudou na Universidade Federal de Santa Maria (UFSM) no estado do Rio Grande do Sul no Brasil. Por sua vez, Szymańska et al. (2015) tiveram contato com as microalgas na bacia do Lago Luknajno, pertencente à Reserva da Biosfera da Organização das Nações Unidas para a Educação, a Ciência e a Cultura (UNESCO). Estas eram comumente encontradas junto a outras algas filamentosas, formando esteiras flutuantes margeando os corpos d'água ou cobrindo substratos submersos de materiais vegetais vivos ou mortos.

Figura 2: Micrografia da microalga Oedogonium sp.

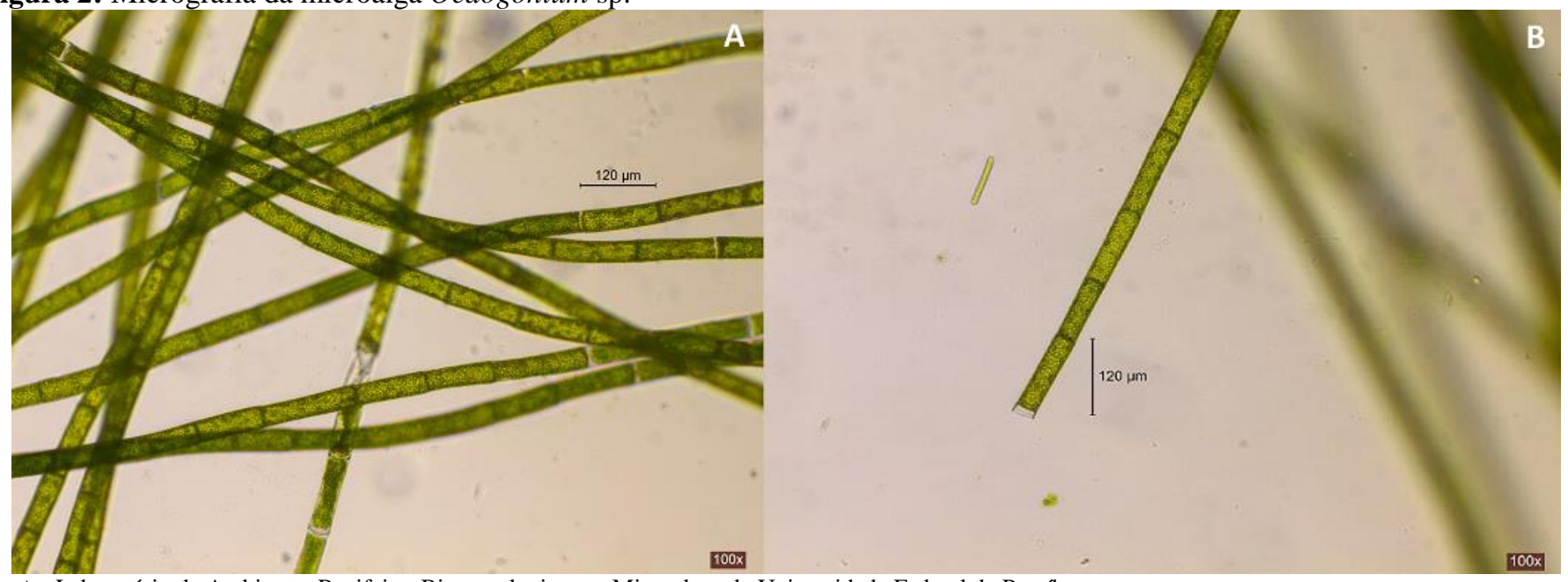

Fonte: Laboratório de Ambientes Recifais e Biotecnologia com Microalgas da Universidade Federal da Paraíba.

Após a identificação, a alga foi levada para o Laboratório de Materiais e Química Ambiental (LABMAQ) da UFPB para realização das análises necessárias. Inicialmente a biomassa in natura (Figura 3) passou por um processo de limpeza dos materiais sólidos como pequenas folhas e pequenos caramujos, para então ser submetida à análise de umidade.

As amostras foram secas em uma estufa de circulação de ar forçada por $24 \mathrm{~h}$ distribuídas em 3 dias, a $110^{\circ} \mathrm{C}$ para então serem realizadas as análises em base seca. $\mathrm{O}$ processo de secar a amostra é muito importante para evitar a decomposição da matéria, que por conter muita umidade se degrada rapidamente. É aconselhável encontrar medidas que promovam a secagem da biomassa economizando o máximo de energia possível, de modo que, submeter à amostra a luz solar é uma boa opção.

Depois de seca, a biomassa foi separada manualmente, de modo a encontrar-se como exposto na Figura 4, para então ser submetida às análises imediata e de poder calorífico. Para cada análise foram feitas duas amostras, cada uma com $1 \mathrm{~g}$ da biomassa, pesadas na balança de precisão, onde o resultado final de cada é tido pela média da duplicata das amostras analisadas.
Figura 3: Biomassa in natura da microalga Oedogonium sp.

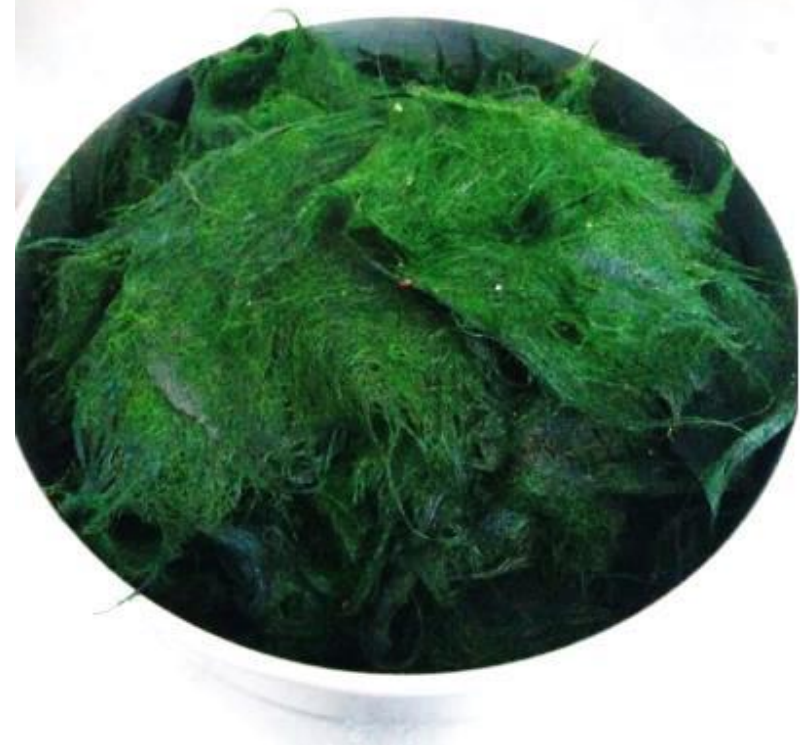

Fonte: Autoras, 2018 
Figura 4: Biomassa seca de microalga Oedogonium sp.

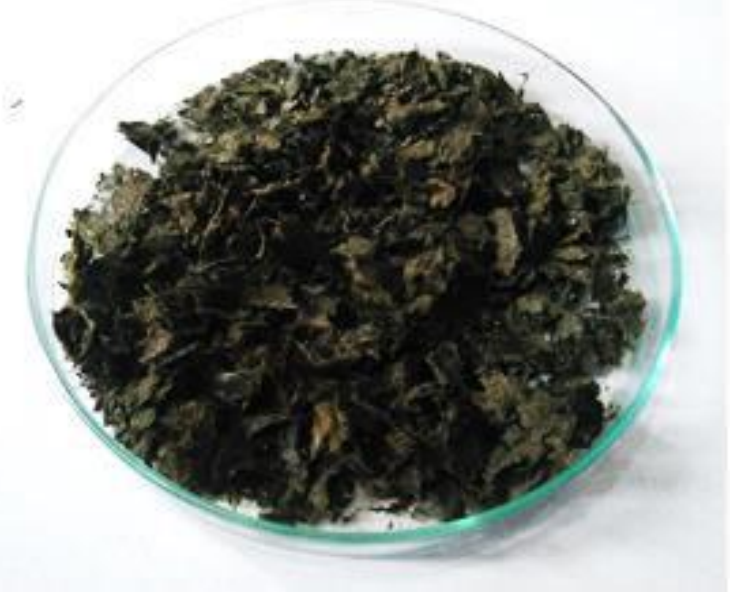

Fonte: Autoras, 2018

O teor de umidade foi obtido pela balança de umidade digital mediante duas amostras, cada qual com $1 \mathrm{~g}$ da biomassa in natura. $\mathrm{O}$ processo é simples, fazendo-se necessário apenas o correto manuseio do equipamento e aguardar o seu tempo de funcionamento.

Para determinação do teor de voláteis seguiu-se a norma ASTM E872, na qual as amostras foram secas na balança de umidade, separadas em dois cadinhos diferentes, cada qual com $1 \mathrm{~g}$ de amostra em ensaios separados.

$\mathrm{O}$ processo de queima da biomassa acontece de forma rápida, onde a amostra é aquecida por um total de 7 minutos com o forno a temperatura de $950^{\circ} \mathrm{C}$. Nos primeiros 2 minutos o cadinho é colocado na porta do forno mufla e nos 5 minutos seguintes ele é aquecido dentro do forno.

Passado o tempo de aquecimento na mufla, o cadinho é retirado para esfriar até perder a cor avermelhada devido ao excesso de calor, para em seguida esfriar no dessecador até a temperatura ambiente. Por fim o teor de umidade pode ser determinado pelas Equações 1, 2 e 3:

$$
\begin{aligned}
& \text { Mresidual }=\mathrm{Mf}(\mathrm{am}+\mathrm{cad})-\mathrm{Mcad} \\
& \mathrm{X}=(\text { Mresidual } / \mathrm{Mi}(\mathrm{am})) .100 \\
& \% \mathrm{TV}=100-\mathrm{X}
\end{aligned}
$$

Em que: TV, teor de voláteis (\%); Mresidual, massa da amostra após a queima (g); Mcad, massa do cadinho com a tampa (g); Mf(am+cad), soma das massas do cadinho com a tampa e da $\operatorname{amostra}(\mathrm{g})$; Mi(am), massa inicial da amostra (g).

A determinação do teor de cinzas foi segundo a norma ASTM E1755, cujo processo envolve secar as duas amostras de biomassa cada qual com 1g, na balança de umidade, dispor o cadinho a temperatura ambiente na Mufla e aguardar o aquecimento do forno até $575^{\circ} \mathrm{C}$.

Esse aquecimento ocorre de forma controlado a uma taxa de $10^{\circ} \mathrm{C} / \mathrm{min}$, no qual a Mufla deve atingir $250^{\circ} \mathrm{C}$ e manter-se nessa temperatura por $30 \mathrm{~min}$, e em seguida é programada para chegar a $575^{\circ} \mathrm{C}$ permanecendo assim por mais 2 horas, até que todo o carbono tenha queimado.

Em sequência a amostra é colocada no dessecador até atingir a temperatura ambiente, permitindo que seja feita a sua pesagem após a queima, concluindo com os cálculos do teor de cinzas propriamente dito nas Equações 4 e 5.

$$
\begin{aligned}
& \text { Mcinzas }=\operatorname{Mf}(\mathrm{am}+\mathrm{cad})-\mathrm{Mcad} \\
& \% \mathrm{TC}=(\text { Mcinzas } / \mathrm{Mi}(\mathrm{am})) .100
\end{aligned}
$$

Em que: TC, teor de cinzas (\%); Mcinzas, massa de cinzas após a queima (g); Mf(am+cad), massa do cadinho com a amostra (g); Mcad, massa do cadinho(g); Mi(am), massa inicial da $\operatorname{amostra}(\mathrm{g})$.

A determinação do teor de carbono fixo foi realizado de acordo com a equação 6 , sendo uma relação entre o teor de cinzas e o teor de material volátil para cada amostra realizada.

$$
\mathrm{CF}=100-(\mathrm{TC}+\mathrm{TV})
$$

Em que: $\mathrm{CF}$, carbono fíxo; $\mathrm{TC}$, teor de cinzas; $\mathrm{TV}$, teor de voláteis.

O PCS foi determinado a partir da bomba calorimétrica, modelo IKA C200, segundo a norma ASTM D5865-13. Para realizar a análise de Termogravimetria (TG) e Termogravimetria Derivada (DTG), a biomassa que antes tinha sido fragmentada manualmente, foi processada no liquidificador MOD. BR 3,5 L da marca COLOMBO e em seguida peneirada na peneira com furos de $250 \mu \mathrm{m}$ (60 mesh), mantendo um padrão de granulometria das partículas.

As análises foram realizadas no equipamento TGA Q50 V6.7 da TA Instruments. O experimento foi realizado em atmosfera de nitrogênio com uma vazão de $50 \mathrm{ml} / \mathrm{min}$, cadinho de platina, peso da amostra em torno de $10 \mathrm{mg}$ e temperatura programada partindo da temperatura ambiente até $900{ }^{\circ} \mathrm{C}$ a uma taxa de aquecimento de $10^{\circ} \mathrm{C} / \mathrm{min}$.

Para realizar a densificação da biomassa foram feitas três amostras, das quais a primeira (amostra 1) foi peneirada em uma malha 60 mesh e as duas restantes (amostra 2 e 3 ) foram processadas no liquidificador industrial, de modo a deixar as partículas mais semelhantes as da análise imediata.

A biomassa foi densificada em forma de pastilha para avaliar a viabilidade da produção de pellets com as amostras utilizadas. Não foi necessário utilizar nenhum aglutinante junto à biomassa para realizar sua compactação, fazendo-se o uso apenas da prensa hidráulica, Marcon, que é operada manualmente e possui capacidade de operação de 30 toneladas.

O molde utilizado para produção das pastilhas densificadas possui $5 \mathrm{~cm}$ de diâmetro, é feito de aço, o qual foi submetido a uma carga de 10 toneladas para cada amostra que foi colocada em seu interior. Para a produção de cada pastilha foram utilizados aproximadamente $6 \mathrm{~g}$ da biomassa seca da microalga (Figura 5).

Figura 5: Prensa hidráulica, Marcon, com amostra de biomassa no recipiente de aço.

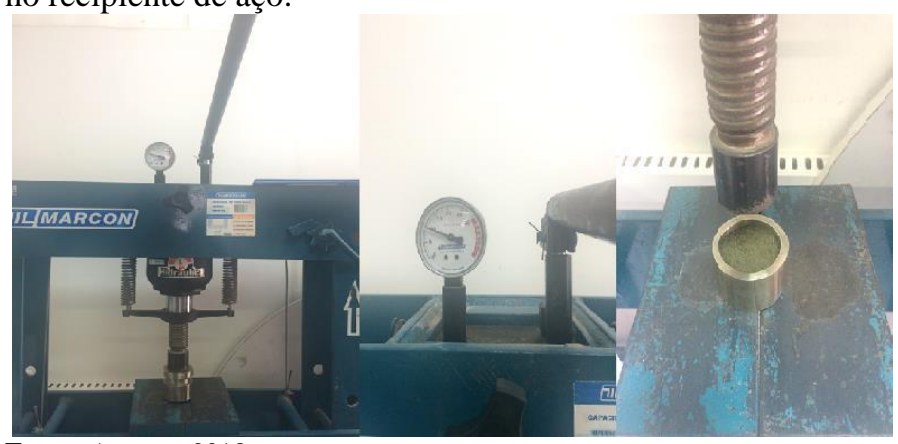

Fonte: Autoras, 2018 


\section{RESULTADOS E DISCUSSÃO}

Por meio da análise imediata foi possível observar o teor de umidade, teor de material volátil, teor de cinzas e teor de carbono fixo. Além disso, foi determinado o poder calorífico superior. Os resultados médios para estas análises podem ser observados na Tabela 1, em que, observa-se o alto teor de umidade em base úmida da amostra in natura, $88,37 \%$, fato que do ponto de vista energético configura-se como um problema à queima da biomassa, uma vez que, parte do calor gerado será utilizada para evaporar a água presente na amostra e não para gerar energia. Sendo assim, faz-se necessário algum procedimento para retirada do excesso de umidade, que por sua vez deve ser viável economicamente e tecnologicamente.

Tabela 1: Análise imediata (teor de umidade, teor de material volátil, teor de cinzas e teor de carbono fixo) e poder calorífico da microalga Oedogonium sp.

\begin{tabular}{lc}
\hline \multicolumn{2}{c}{ Valores Médios } \\
\hline Teor de Umidade (\%) & $88,37 \pm 1,13$ \\
Teor de Voláteis (\%) & $71,68 \pm 1,96$ \\
Teor de Cinzas (\%) & $18,09 \pm 1,79$ \\
Teor de carbono fixo (\%) & 10,23 \\
PCS (MJ/Kg) & $16,13 \pm 0,87$ \\
\hline
\end{tabular}

A umidade da amostra foi retirada através da estufa de circulação de ar. No entanto, outros métodos podem ser utilizados, como a secagem natural ao sol e utilização de secadores que aproveitam energia solar. Ainda é possível realizar a associação da produção de energia a partir das microalgas a plantas industriais, como usinas de cana-deaçúcar, onde é possível reaproveitar o calor gerado por algum processo na secagem das microalgas.

$\mathrm{O}$ teor de material volátil da microalga Oedogonium sp. foi igual a 71,68 \%, um valor alto e muito próximo aos 75,33\% encontrados por Hansted et al. (2016) para biomassa sólida da espécie arbórea Leucaena leucocephala (leucena). Este valor expressivo caracteriza a alga em estudo, como um combustível mais inflamável e consequentemente de queima rápida. Conhecer essa propriedade do combustível possibilita seu correto emprego e manipulação, uma vez que para queima direta um alto teor de material volátil é satisfatório devido a sua fácil ignição. No entanto, Vieira et al. (2013), chama atenção para o fato de que um processo de combustão rápido é mais difícil de controlar, além de afetar o processo como o todo.

O teor de cinzas foi de 18,09\% também se apresentou um pouco elevado, principalmente ao ser comparado com o teor de $5,68 \%$ dos briquetes da cana-de-açúcar (PADILLA et al., 2016). O teor de carbono fixo por sua vez, foi $10,23 \%$, valor que condiz com os obtidos nas análises anteriores de teor de umidade, teor de cinzas e material volátil, uma vez que ele diz respeito à porcentagem da amostra que resta após subtrair essas parcelas citadas. É desejável que o teor de carbono fixo seja elevado, pois ele representa a quantidade de carbono que vai ser efetivamente convertido em energia.

O poder calorífico superior obtido foi de $16,13 \mathrm{MJ} / \mathrm{kg}$, mostrando-se satisfatório, indicando o bom potencial para conversão energética da microalga. O PCS encontrado foi superior ao de biomassas tradicionais apresentadas por Brasil
(2013), como o a lenha catada e a lenha comercial com valores energéticos de $13,819 \mathrm{MJ} / \mathrm{kg}$ (ou 3.300,00 kcal $/ \mathrm{kg}$ ) cada, que além de possuírem um menor PCS, emitem $\mathrm{CO}_{2}$ atmosférico. De acordo com Müzel et al. (2014), a madeira Florestal de espécie Hevea brasiliensis apresentou um PCS igual a 17,87 $\mathrm{MJ} / \mathrm{kg}$ (ou $4.157,80 \mathrm{kcal} / \mathrm{kg}$ ), valor um pouco mais elevado, mas muito próximo ao da microalga em estudo.

A densificação da biomassa foi feita em forma de pastilhas (Figura 7) para avaliar a viabilidade da produção de pellets com a microalga Oedogonium sp, bem como seu poder energético. Para isso as análises foram comparadas com as normas europeia, CEN/TS 14961-2, a SS 1871 20, sueca, e a ISO 17225-6.

As pastilhas possuem $5 \mathrm{~cm}$ de diâmetro, pesam em torno de $6 \mathrm{~g}$, com $3 \mathrm{~mm}$ de espessura para primeira amostra, $3,4 \mathrm{~mm}$ para a segunda e $3,6 \mathrm{~mm}$ para a terceira. O processo de densificação não altera a maioria das características já analisadas, no entanto a umidade foi novamente medida após a biomassa ter secado na estufa por 24 horas aproximadamente e ter sido submetida à prensa.

Figura 6: Biomassa densificada em forma de pastilhas da microalga Oedogonium sp.

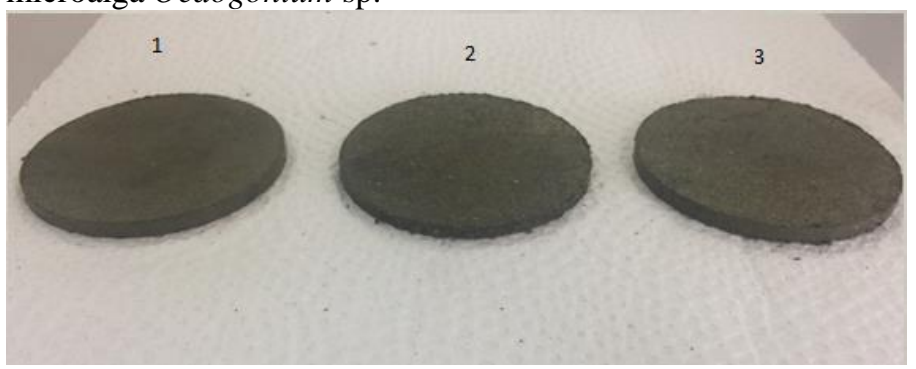

Fonte: Autoras, 2018.

A umidade em base seca foi de $7,85 \%$ para a amostra 1 ; $7,45 \%$ amostra 2 e $7,35 \%$ para a amostra 3 , resultando numa média de $7,55 \% \pm 0,26$. A densidade aparente que foi medida por meio do método do picnômetro apresentou uma média de $1271,50 \mathrm{~kg} / \mathrm{m}^{3}$. Os teores de cinza, material volátil e carbono fixo mantiveram-se iguais a 18,09\%, 71,68\% e 10,23\% respectivamente, uma vez que essas parcelas não se alteram após serem submetidos a secagem e a densificação, motivo pelo qual não foi necessário repetir essas análises. O mesmo acontece com o PCS, que se manteve igual a $16,13 \mathrm{MJ} / \mathrm{kg}$.

Dentre as normas disponíveis para pellets de madeira observou-se que, de acordo com a norma sueca SS 1871 20, para pellets, da classe G3, a biomassa densificada Oedogonium sp atende as especificações técnicas para os valores de densidade aparente $\left(\geq 500 \mathrm{~kg} / \mathrm{m}^{3}\right)$, teor de umidade $(\leq 12 \%)$ e poder calorífico $(\geq 15,0 \mathrm{MJ} / \mathrm{Kg})(\mathrm{SS} 187180,1999)$. O mesmo aconteceu para a norma europeia CEN/TS 14961-2 da classe B, que requer densidade aparente maior que $600 \mathrm{~kg} / \mathrm{m}^{3}$, teor de umidade inferior a $10 \%$ e poder calorífico superior a $16 \mathrm{MJ} / \mathrm{Kg}$ (DIN, 2011).

Muitos países normatizaram seus próprios padrões de qualidade para pellets, no entanto, o Brasil ainda não implementou os seus (SPANHOL et al.,2015). No intuito de unir a certificação dessas normas, surgiu a International Organization for Standardization-ISO 17225 (2014), na qual, 
os pellets classificam-se em comerciais, industriais e não lenhosos (GARCIA et al., 2018).

Diante da norma ISO 17225-6, em sua classe A, para pellets não lenhosos, as pastilhas densificadas de Oedogonium sp atenderam bem as especificações para densidade aparente, teor de umidade e poder calorífico, cujos seus respectivos valores normatizados a serem atingidos são de $\geq 600 \mathrm{~kg} / \mathrm{m}^{3}$, $\leq$ $12 \%$ e $\geq 14,1 \mathrm{MJ} / \mathrm{Kg}$, configurando-se como a melhor classificação normatizada para as pastilhas (ISO 17225, 2014).

Diante dos valores totalmente satisfatórios para a densidade aparente e teor de umidade em comparação com as normas de padronização e qualidade para pellets e com o poder calorífico acima dos padrões, entende-se que a microalga Oedogonium sp apresenta um bom potencial energético e boas condições para produção da biomassa densificada em forma de pellets.

As curvas da TG e DTG são resultado da combustão e pirólise de uma determinada amostra, sob uma variação de temperatura controlada. A análise iniciou-se com uma massa igual a $10,551 \mathrm{mg}$ e sofreu uma perda de $9,212 \mathrm{mg}$, representando uma degradação de cerca de $87 \%$ de sua massa inicial. Na Figura 7 é possível observar a curva de degradação térmica da microalga Oedogonium sp em atmosfera inerte.

Figura 7: Curvas de Termogravimetria (TG) e Termogravimetria Derivada (DTG), ao longo da variação de temperatura $(\mathrm{T})$, da microalga Oedogonium sp.

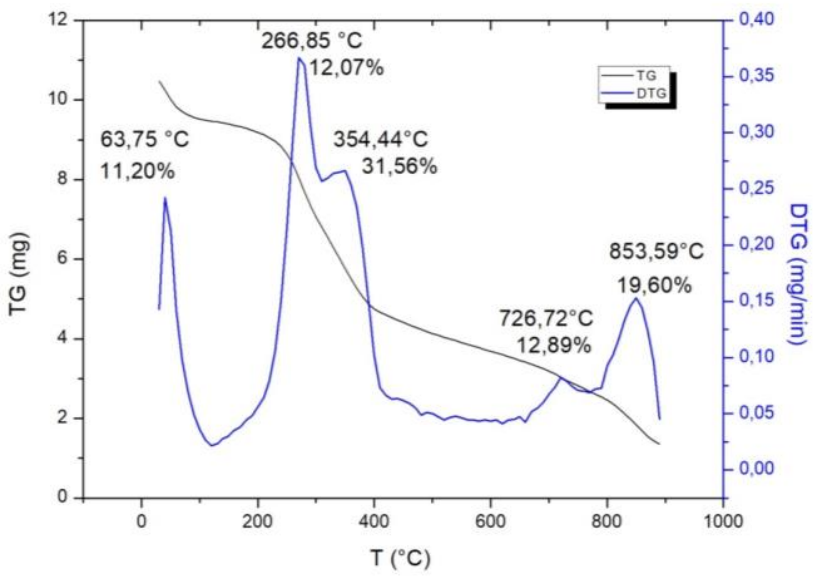

Pela curva da TG nota-se que a perda de massa ocorre em três etapas, que segundo Rambo et al. (2015), corresponde a uma característica típica da degradação térmica da biomassa lignocelulósica, a primeira delas comumente associada a perda de umidade, ocorre entre $50^{\circ} \mathrm{C}$ e $100^{\circ} \mathrm{C}$, seguida da decomposição da hemicelulose e celulose (carboidratos) entre $250^{\circ} \mathrm{C}$ e $400^{\circ} \mathrm{C}$, finalizando com uma etapa lenta e contínua correspondente a degradação da lignina a temperaturas acima de $400^{\circ} \mathrm{C}$.

Analisando a Figura 7, é notável a ocorrência da etapa correspondente a perda de umidade residual da amostra, no intervalo de $23^{\circ} \mathrm{C}$ a $117^{\circ} \mathrm{C}$, isso se dá com um decréscimo de $10,13 \%$ da massa inicial ou $1,069 \mathrm{mg}$. Ainda nesta etapa existe um pico máximo em $63,75{ }^{\circ} \mathrm{C}$ na curva da $\mathrm{DTG}$, referente à perda de umidade.

A segunda etapa acontece entre $117^{\circ} \mathrm{C}$ e $418^{\circ} \mathrm{C}$, com uma perda de 46,39\% da massa inicial ou 4,895 $\mathrm{mg}$, que de acordo com Carrier et al. (2011), corresponde a degradação da hemicelulose e celulose. Desse modo, os dois picos existentes na DTG zoneados de $256,59{ }^{\circ} \mathrm{C}$ a $302{ }^{\circ} \mathrm{C}$, e de $308,58^{\circ} \mathrm{C}$ a $406,89{ }^{\circ} \mathrm{C}$, correspondem à formação dos produtos da degradação da hemicelulose e celulose.

Por último, a terceira etapa acontece entre $418^{\circ} \mathrm{C}$ e $900^{\circ} \mathrm{C}$, com uma perda $31,50 \%$ da massa inicial ou $3,324 \mathrm{mg}$. Na curva da DTG é possível observar alguns picos, com destaque para aquele cujo pico de máxima temperatura ocorre em $732,83^{\circ} \mathrm{C}$, entre $701^{\circ} \mathrm{C}$ e $775,15^{\circ} \mathrm{C}$, e ao último pico com temperatura máxima de $852,20^{\circ} \mathrm{C}$, localizado entre $791,62^{\circ} \mathrm{C}$ e $885,21^{\circ} \mathrm{C}$.

Segundo Singh et al. (2016), a presença dos picos na última etapa de degradação da biomassa se dá devido a pirólise da lignina, sendo esta dividida em reações que ocorrem em uma ampla faixa de temperaturas, indicando a presença de mais de um pseudo componente (álcool sinapílico, álcool coniferílico e álcool guaiacila).

O último pico desta etapa apresenta-se de forma atípica no fim da decomposição, sendo um indicativo de que ainda existe matéria a ser degrada, como por exemplo, voláteis pesados. As temperaturas e perdas de massa para cada etapa citada acima podem ser observadas na Tabela 2.

Tabela 2: Temperaturas e perda de massa das etapas da degradação da microalga Oedogonium sp.

Intervalos de temperatura Temperatura de pico $\left({ }^{\circ} \mathrm{C}\right)$

Perda de massa (\%)

Perda de massa (mg) Componente degradado

\begin{tabular}{ccccc}
$23^{\circ} \mathrm{C}-117^{\circ} \mathrm{C}$ & 63,75 & 10,13 & 1,069 & Umidade \\
$117^{\circ} \mathrm{C}-418^{\circ} \mathrm{C}$ & 266,85 & 46,39 & 4,895 & - \\
$418^{\circ} \mathrm{C}-900^{\circ} \mathrm{C}$ & 852,20 & 31,50 & 3,324 & - \\
\hline
\end{tabular}

\section{CONCLUSÕES}

A microalga Oedogonium sp. apresenta um bom potencial energético, pelo elevado poder calorífico superior, podendo ser um bom substituto a biomassas sólidas tradicionais e emissoras de $\mathrm{CO}_{2}$. pellets.
A biomassa da microalga Oedogonium sp. tem boa viabilidade na produção de pellets, oportunizando seu transporte e comercialização como produto para combustão.

\section{AGRADECIMENTOS}

À Universidade Federal da Paraíba pelo apoio nesta pesquisa através do Laboratório de Materiais e Química Ambiental e do Laboratório de Ambientes Recifais e Biotecnologia com Microalgas. 


\section{REFERÊNCIAS}

ANDRADE, D. S.; FILHO, A. C. Microalgas de Águas Continentais: Potencialidades e desafios do cultivo. IAPAR, v. $1,2014$.

BRASIL, B. Microalgas: a $3^{\text {a }}$ geração de biocombustíveis no Brasil. Embrapa Agroenergia-Artigo de divulgação na mídia (INFOTECA-E), 2014.

BRASIL. Ministério de Minas e Energia. Balanço energético nacional 2013: Ano base 2012. Empresa de Pesquisa Energética - Rio de Janeiro: EPE, 2013.

BRENNAN, L.; OWENDE, P. Biofuels from microalgaea review of technologies for production, processing, and extractions of biofuels and co-products. Renewable and sustainable energy reviews, v. 14, n. 2, p. 557-577, 2010. 10.1016/j.rser.2009.10.009.

CARDOSO, A. da S.; VIEIRA, G. E. G.; MARQUES, A. K. O uso de microalgas para a obtenção de biocombustíveis. Revista Brasileira de Biociências, v. 9, n. 4, p. 542-549, 2011. ISSN 1980-4849.

CARRIER, M.; LOPPINET-SERANI, A.; DENUX, D.; LASNIER, J. M.; HAM-PICHAVANT, F.; AYMONIER, F. C. C. Thermogravimetric analysis as a new method to determine the lignocellulosic composition of biomass. Biomass and Bioenergy, v. 35, n. 1, p. 298- 307, 2011. 10.1016/j.biombioe.2010.08.067.

CARRIJO, R. dos S.; SILVA, V. C. F.; SANTOS, A. C. M. dos.; COSTA, M. F.; FERREIRA, T. P. Uso de microalgas para a produção de biodiesel: vantagens e limitações. Revista Eletrônica de Energia, v. 5, n. 1, 2015.

CORTEZ, L. A. B.; LORA, E. S.; GÓMEZ, E. O. Biomassa para energia. 1 ed. Campinas: Editora da UNICAMP, 2008. $736 \mathrm{p}$.

CASSOL, A. P. V.; OLIVEIRA, M. A.; FIGUEIREDO, M. C. dos S.; LUZ, D. S. da; SARTORI, G. M. S.; MARCHESAN, E. Microalgas em cultura de arroz: influência de diferentes manejos de adubação em áreas com residual de herbicidas (imidazolinonas). Iheringia. Série Botânica, v. 68, n. 2, p. 261271, 2013.

DIN EN 14961-2: Solid biofuels - Fuel specifications and classes - Part 2: Wood pellet's for non-industrial use. Alemanha: CEN: 15 p. 2011.

DO AMARAL, F. C. S.; TAVARES, S. R de L. Diferença do teor de fibra da cana-de-açúcar para fins energéticos motivada pelo bioma. Embrapa Solos-Documentos (INFOTECA-E), 2013.

GARCIA, D. P.; CARASCHI， J. C.; VENTORIM， G.; PRATES, G. A.; PROTÁSIO, T. de P. Qualidade dos pellets de biomassas brasileiras para aquecimento residencial: padrões da norma ISO 17225. Revista Ciência da Madeira, v. 9, n. 1, 2018. 10.15210/cmad.v9i1.11007.

HANSTED, A. L. S.; NAKASHIMA, G. T.; MARTINS, M. P.; YAMAJI, F. M. Caracterização físico-química da biomassa de Leucaena leucocephala para produção de combustível sólido. Revista Virtual de Química, v. 8, n. 5, 2016.

HOMIAK, J. A.; MORESCO, C. Produção de biodiesel utilizando microalgas. SaBios-Revista de Saúde e Biologia, v. 9, n. 2, p. 65-74, 2014.

ISO 17225-6: 2014: Solid biofuels - Fuels especication and classes - Part 6: Graded non-woody pellets. Brussels, 2014.

MARTINE, G.; TORRES, H. G.; FREIRE DE MELLO, L. Cultura do consumo e desenvolvimento econômico na era de mudanças climáticas. In: George Martine. (Org.). População e Sustentabilidade na era das mudanças ambientais globais. Belo Horizonte: ABEP, p. 19-32, 2012.

MENEZES, R. S.; LELES, M. I. G.; SOARES, A. T.; FRANCO, P. I. B. E M.; ANTONIOSI, N. R. F.; SANT'ANNA, C. L.; VIEIRA, A. A. H. Avaliação da potencialidade de microalgas dulcícolas como fonte de matériaprima graxa para a produção de biodiesel. Química Nova, v. 36, n. 1, p. 10-15, 2013. 10.1590/S0100-40422013000100003.

MÜZEL, S. D.; OLIVEIRA, K. A. de; HANSTED, F. A. S.; PRATES, G. A.; GOVEIA, D. Poder Calorífico da Madeira de Eucalyptus Grandis e da Hevea Brasiliensis. Revista Brasileira de Engenharia de Biossistemas, Campus de Itapeva, SP, v. 8 n.2, p.166-172, 2014. 10.18011/bioeng2014v8n2p166-172.

OEDOGONIUM. In Encyclopædia Britannica. 2019. Disponível em: <https://www.britannica.com/science/Oedogonium> Acesso em: 03 de julho de 2019.

OHSE, S.; DERNER, R. B.; OZERIO, R. A.; CUNHA, P. C. R.; LAMARCA, C. P.; SANTOS, M. E. dos; MENDES, L. B. B. Revisão: Sequestro de Carbono Realizado por Microalgas e Florestas e a Capacidade de Produção de Lipídios pelas Microalgas. Insula, n. 36, p. 39-74, 2007.

PADILLA, E. R. D.; PIRES, I. C. S. A.; YAMAJI, F. M.; FANDIÑO, M. M. Produção e Caracterização Físico-Mecânica de Briquetes de Fibra de Coco e Palha de Cana-deAçúcar. Revista Virtual de Química, v. 8, n. 5, 2016.

PEREIRA, A. O. K.; HORN, L. F. D. R. (Org.). Relações de consumo: globalização. 1. ed. Caxias do Sul: EDUCS, 2010. v. 1. 268p.

PEREIRA, C. M. P.; HOBUSS, C. B.; MACIEL, J. V.; FERREIRA, L. R.; PINO, F. B. D.; MESKO, M. F.; LOPES, E. J.; NETO, P. C. Biodiesel Renovável Derivado de Microalgas: 
Avanços e Perspectivas Tecnológicas. Química Nova, v. 35, n. 10, p. 2013-2018, 2012. 10.1590/S0100-40422012001000022.

RAMBO, M. K. D.; RAMBO, M. C. D.; ALMEIDA, K. J. C. R.; ALEXANDRE, G. P. Estudo de análise termogravimétrica de diferentes biomassas lignocelulósicas utilizando a análise por componentes principais. Ciência e natura, v. 37, n. 3, p. 862868, 2015. 105902/217946018332.

SCOTT, S. A.; DAVEY, M. P.; DENNIS, J. S.; HORST, I.; HOWE, C. J.; LEA-SMITH, D. J.; SMITH, A. S. Biodiesel from algae: challenges and prospects. Currentopinion in biotechnology, v. 21, n. 3, p. 277-286, 2010. 10.1016/j.copbio.2010.03.005.

SINGH, R.; KRISHNA, B. B.; MISHRA, G.; KUMAR, J.; BHASKAR, T. Strategies for selection of thermo-chemical processes for the valorisation of biomass. Renewable Energy, v. 98, p. 226-237, 2016. 10.1016/j.renene.2016.03.023.

SPANHOL, A.; NONES, D. L.; KUMABE, F. J. B.; BRAND, M. A. Qualidade dos pellets de biomassa florestal produzidos em Santa Catarina para a geração de energia. Floresta, v. 45, n. 4, p. 833-844, 2015. 10.5380/rf.v45i4.37950.

SWEDISH STANDARDS. SS187180: Biofuels and PeatDetermination of mechanical durability of pellets and briquettes. Classification Swedish Standards. Stockholm, 1999.

SZYMAŃSKA, H.; KRZYK, A.; METRAK, M. Some species of Oedogoniales (Chlorophyceae) from small astatic water bodies in the post-agricultural landscape (Masurian Landscape Park, NE Poland). Phytotaxa, v. 192, n. 3, p. 121-144, 2015. 10.11646/phytotaxa.192.3.1.

VIEIRA, A. C.; SOUZA, S. N. M. de; BARICCATTI, R. A.; SIQUEIRA, J. A. C.; NOGUEIRA, C. E. C. Caracterização da casca de arroz para geração de energia. Varia Scientia Agrárias, v. 3, n. 1, p. 51-57, 2013. 